\title{
Improved Bone Formation in Osteoporotic Rabbits with the Bone Morphogenetic Protein-2 (rhBMP-2) Coated Titanium Screws Which Were Coated By Using Plasma Polymerization Technique
}

\author{
Salih Gulsen ${ }^{*}$, Dilek Cokeliler ${ }^{2}$, Hilal Goktas ${ }^{3}$, Aysu Kucukturhan ${ }^{2}$, Bilgehan Ozcil $^{2}$, Hakan Caner $^{1}$ \\ ${ }^{1}$ Baskent University Medical Faculty Hospital, Neurosurgery, Maresal Fevzi Cakmak cad.10. sok. No: 45, Ankara 06540, \\ Turkey; ${ }^{2}$ Başkent University, Biomedical Engineering Department, Ankara, Turkey; ${ }^{3}$ Canakkale Onsekiz Mart University, \\ Physics Department, Ankara, Turkey
}

\author{
Citation: Gulsen S, Cokeliler D, Goktas H \\ Kucukturhan A, Ozcil B, Caner H. Improved \\ Bone Formation in Osteoporotic Rabbits with \\ the Bone Morphogenetic Protein-2 (rhBMP-2) \\ Coated Titanium Screws Which Were Coated \\ By Using Plasma Polymerization Technique. OA \\ Maced J Med Sci. 2014 Jun 15; 2(2):198-208. \\ http://dx.doi.org/10.3889/oamjms.2014.031 \\ Key words: Bone morphogenic protein; screw \\ Titanium; osteoporosis. \\ Correspondence: Salih Gulsen, MD. \\ Department of Neurosurgery Faculty of \\ Medicine, Baskent University Medical Faculty \\ Medicine, Baskent University Medical Faculty \\ Department of Neurosurgery, Fevzi Cakmak \\ Caddesi 10. Sokak no. 45, Cankaya, \\ Bahcelievler, Ankara 06490. Turkey. Business \\ 3122237333. E.mail: salihgulsen07@gmail.com \\ Received: 24-Mar-2014; Revised: 18-Apr- \\ 2014: Accepted: 21-Apr-2014; Online first: \\ 15-May-2014 \\ Copyright: () 2014 Gulsen et al. This is an \\ open access article distributed under the terms \\ of the Creative Commons Attribution License, \\ which permits unrestricted use, distribution, \\ and reproduction in any medium, provided the \\ original author and source are credited. \\ Competing Interests: The authors have \\ declared that no competing interests exist.
}

\begin{abstract}
Delaying of bone fusion in osteoporotic patients underwent spinal stabilization surgery leads to screw loosening, and this causes pseudoarticulation, mobility and fibrosis at vertebral segments. To prevent these complications, the screws coated with recombinant bone morphogenetic protein-2 (rhBMP-2) could be used. To verify this hypothesis, we coated 5 Titanium screws with rhBMP-2 using plasma polymerization method, and also used 10 uncoated screws for making comparison between coated and uncoated screws in different groups. And 15 skeletally mature white New Zealand female rabbits were assigned into three different groups: Group $1(\mathrm{~N}=5)$ : No osteoporosis induction and insertion of uncoated Titanium screw into right sacrum of each rabbit in group 1; group $2(\mathrm{~N}=5)$ : Osteoporosis induction and insertion of uncoated Titanium screw into right sacrum of each rabbit in group 2; group $3(\mathrm{~N}=5)$ rhBMP-2 coated Titanium screw inserted into right sacrum of each rabbit in group 3 . In summary, using of these coated screws provides new bone formation, but causes less fibrosis and less inflammation than uncoated screws at the interface between the coated screw and bone. Then the plasma polymerization technique provides controlled releasing of rhBMP-2 from the screw to the bone tissue in osteoporotic rabbits.
\end{abstract}

\section{Introduction}

Pedicle screw loosening is a problem in patients with osteoporosis [1-5]. Pedicle bone quality decreases in osteoporosis, and decreased bone quality leads to decreased pull-out strength and loosening of the pedicle screws $[1,5,6]$. Then, loosening of pedicle screws result in pseudoarthrosis and mobilization of the vertebral segment $[1,5,6]$. This leads to a cycle of fibrosis and screw loosening $[5,6]$.

Bone fusion provides permanent stability while pedicle screws provide temporal spinal stability $[1,7-10]$. Since the occurence of the fusion takes about six months after spinal stabilization surgery, pedicle screws should provide stabilization during this period $[10,11]$.

Bone fusion could not happen unless providing stabilization of the spinal column [10, 11]. For example; insuficent bone matrix of the osteoporotic vertebra could not hold the Titanium screws due to insufficient osteointegration of the screws, and these screws get loose with time and pulling out from the vertebral body before the fusion is completed $[1,2,6,7]$.

Bone morphogenetic protein-2 (rhBMP-2) has been used to improve biologic bonds between bone 
and Titanium screw $[12,13]$. Using of this protein causes secretion of osteoinductive growth factors, and it attracts osteoprogenitor cells [12, 13]. However, it has some drawbacks, including bone overgrowht and various immune reactions in patients with undergoing spinal fusion procedures [14-16]. In addition, high dose Bone morphogenetic protein-2 (rhBMP-2) would be necessary to create its effect on bone tissue because of its short half life, but this high doses may cause the complications mentioned above this line [12-16].

To prevent these complications, different delivery methods has been tried for this protein until now [17-21].

In order to prevent loosening of the screws, we coated Titanium screws with active recombinant bone morphogenetic protein-2 (rhBMP-2) (or immobilized onto the metallic biomaterial) for creating a new bone matrix around the Titanium screws within the osteoporotic vertebral body $[13,16,22,23]$. However, uncontrolled releasing of the rhBMP-2 may cause serious side effects, including bone overgrowth and exagerated immune responses $[14,16]$. To prevent these complications, we used plasma polymerization technique, described in the section of the materials and method, to coat the Titanium screws, and we anchored the rhBMP-2 on the surface of the screw.

To prove our hypothesis, we performed in vivo study on osteoporotic rabbits with Titanium screws coated with active recombinant bone morphogenetic protein-2. We speculated that Titanium screws coated with active recombinant bone morphogenetic protein-2 would provide new bone generation next to the screws, and this new bone generation would hold firmly these screws and prevent them pulling out from the vertebral body until bone formation completed.

In this study, we have two goals. First one is to show bone morphogenetic protein-2 coated screws' effectivity through creating a new bone formation around the implanted screws. The second one is to show controlled releasing of rhBMP-2 into bone with coated screw which had been coated rhBMP-2 using plasma polymerization technique.

\section{Material and Methods}

\section{Materials}

Four-lobe, angled end ring, $12 \mathrm{~mm}, 2.5^{\circ}$ angle, implant grade pure Titanium screws (Blackstone Medical Inc. Springfield, MA/USA) were used during the study. First thin layer was created with using cysteamine monomer $\left(\sim 95 \%, \mathrm{C}_{2} \mathrm{H}_{7} \mathrm{~N}_{5}\right.$, Sigma Aldrich, Germany) for generation of active amine groups. We used $2.5 \%$ (v/v) concentrated glutaraldehyde $\left(\mathrm{C}_{5} \mathrm{H}_{8} \mathrm{O}_{2}\right.$, Acros Organics, $\left.\mathrm{NJ} / \mathrm{USA}\right)$ for chemical activation of the surface. Recombinant bone morphogenetic protein-2 (rhBMP-2) (Medtronic Sofamor Danek, TN/USA) was referred as immobilized bioactive protein. We applied Nuclear Magnetic Rezonans (NMR) analyses using $0.5 \mathrm{ml}$ of deuterium solution per measurements throughout the experiments.

\section{Preparation of Titanium Screw Surfaces}

Plasma Polymerized Thin Film: Plasma process is performed using cysteamine precursor. The sterilized Titanium screws were settled into the plasma generator to obtain amine and thiol functional group on the screws' surfaces with polymerization. Plasma treatment under glow discharge system was provided by electron beam generator. In this technique, electron beam generator was constructed by superposing two discharges namely low pressure dc glow discharge and a high current pulsed one. The first hollow electrode, $\mathrm{K} 1,2$ act as a cathode for both the DC glow discharge and the pulsed one, the second electrode, A2 acts as an anode to establish the glow discharge, while the third electrode A1 was used as an anode for the pulsed discharge as shown in Figure 1. All plasma processes were applied at constant pressure at 1.5 torr pressure under $19 \mathrm{kV}$ glow discharge and 17 minutes exposure time [22, 23]. Screws surfaces were prepared with active amine binding sites after plasma polymerization. These amino functional groups provide glutaraldehyde immobilization to obtain a convenient surface for generating a bioactive protein layer. Plasma polymerized Titanium screws were incubated into the glutaraldehyde solution of $2.5 \%(\mathrm{v} / \mathrm{v})$ in a phosphate buffer at $\mathrm{pH} 7.0$ for 9 hours. The experiment was performed with magnetic stirrer at $275 \mathrm{rpm}$ (lka werke rt10 power) at the temperature of $24-25^{\circ} \mathrm{C}$ [24].

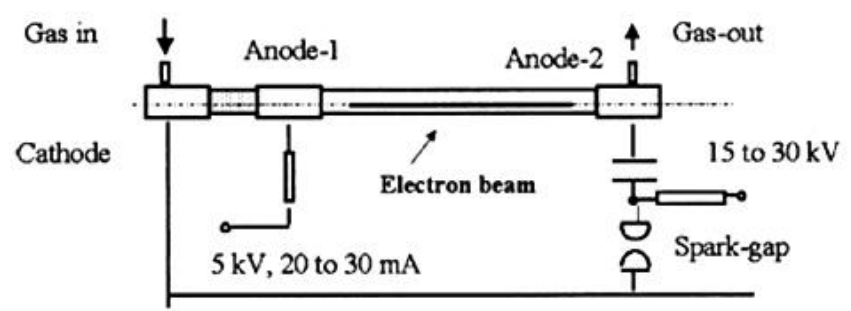

Figure 1: Electron Beam Glow Discharge Plasma Polymerization System.

Scanning Electron Microscopy Analysis: The physical structure of the control group (unmodified Titanium screws) was characterized by Joel JSM 7000f model Scanning Electron Microscopy (SEM) device operating at $20 \mathrm{kV}$ using $\times 450$ magnification. This analysis was repeated after the plasma polymerization of Titanium screws for the state of change on surface physical profile.

Stylus Probe and Non-Contact Surface Profiler: Thicknesses of the plasma polymerized thin film on the reference are measured by DekTac 6M Stylus Probe Surface Profiler. Surface roughness of 
the control group and modified ones were characterized by Zygo New View 6200 non-contact surface profiler [22-24].

Table 1: Elemental analysis of $\mathrm{Ti}$ screws after plasma polymerization.

\begin{tabular}{lcccccc}
\hline Element & $\begin{array}{c}\text { Atom } \\
\%\end{array}$ & Orbit & Reg & Range & Integral & Background \\
\hline $\mathrm{C}$ & 79.5 & $1 \mathrm{~s}$ & $\mathrm{a} 4$ & $295 . .279$ & 15041.9 & 30468 \\
$\mathrm{~N}$ & 0.0 & $1 \mathrm{~s}$ & $\mathrm{a} 3$ & $404.8 . .396 .7$ & -208.2 & 21434 \\
$\mathrm{O}$ & 18.0 & $1 \mathrm{~s}$ & $\mathrm{a} 2$ & $541.8 . .526 .1$ & 7832.6 & 44197 \\
$\mathrm{~S}$ & 2.6 & $2 \mathrm{p}$ & $\mathrm{a} 5$ & $168.3 . .160 .5$ & 1103.4 & 9416 \\
\hline
\end{tabular}

X-Ray Photoelectron Spectroscopy Analysis: The chemical structure of the plasma polymerized thin film prepared surface with cysteamine precursor was characterized by X-Ray photoelectron spectroscopy (XPS) system with $\mathrm{Mg} / \mathrm{Al}$ dual anode (Berlin, Germany). All the scans given in this work was obtained with the $\mathrm{Al}$ source, and recorded at a resolution of $2.3 \mathrm{eV}$ for survey scans and $0.9 \mathrm{eV}$ for core level spectra, at a take-off angle of 65 degrees with respect to the sample surface using ES 200 hemispherical electrostatic energy analyzer equipped with multichannel detector with 18 discrete channels, operation in the constant pass energy mode. The chemical structure of the plasma polymerized thin film was averaged by the X-Ray photoelectron spectroscopy (XPS) process. Elements on the surfaces are identified from the survey spectrum. Atomic concentrations were calculated from the integral peak intensities of the main photoelectron peak for each element identified in the spectrum using a Shirley-type background and the sensitivity factors supplied by the manufacturer of the instrument.

Contact Angle Measurement: Sessile drop contact angle measurements were carried out by pipetting approximately $10 \mu \mathrm{l}$ drop of distilled water onto the sample surfaces and used the Drop Shape Analyzer 100 computer aided microscope to capture images of the drop. Unmodified Titanium screw (control group), plasma polymerized Titanium screw and surface activated Titanium screw by glutaraldeyhde were characterized by contact angle measurements. Those angles were the inner angles between the curvature surface of water drop and the solid surface. And these measurements were done with 5 replicates. It gave and idea for change on surface hydrophilicity and energy for each step. These results are shown at the Table 2.

Table 2: The static contact angles of the water drop on the solid surfaces with sessile drop technique.

\begin{tabular}{ll}
\hline Reference control surfaces & $\left.\mathrm{Q}^{\circ}\right)^{*}$ \\
Unmodified Ti screw & $82.8 \pm 5.6$ \\
Plasma polymerization with cysteamine & $51.9 \pm 3.7$ \\
Glutaraldehyde activation & $36.6 \pm 4.6$ \\
\hline
\end{tabular}

Immobilization of Bioactive Protein: After surface activation, we applied active protein immobilization step. We dissolved $4.2 \mathrm{mg}$ of recombinant bone morphogenetic protein-2 (rhBMP-2) with $3.2 \mathrm{ml}$ sterilized water. We schematically summarized the preparation steps in the Figure 2.
Using time controlled medium, we performed immobilizations of rhBMP-2 onto the screws through 2 and 5 hours with injection for in-vivo test. The proof for immobilization step was provided using $400 \mathrm{MHz}$, standard 16 counts per proton, Bruker 400 Ultrashield model NMR devices at the temperature of $22{ }^{\circ} \mathrm{C}$. Screws were incubated at the $0.5 \mathrm{ml}$ of $4.2 \mathrm{mg}$ rhBMP-2 with solvent $3.2 \mathrm{ml}$ deuterium solution for 2 , 5 and 24 hours and the NMR spectrums of the solution from holder were obtained [22-24].

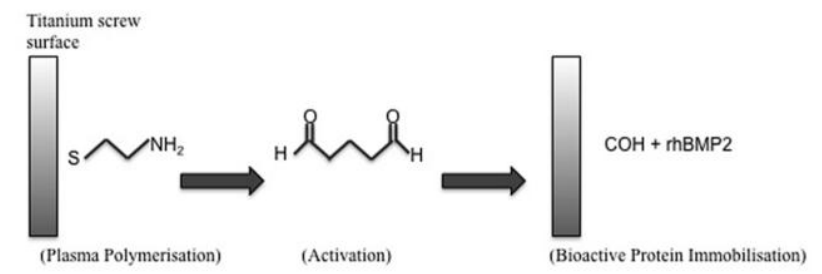

Figure 2: The steps of immobilization of bioactive protein schematically summarized in this figure.

Detection of Residual Protein Following In Vivo Experimentation: After the three months long invivo experiment and continued body fluid contracted medium, five of the bioactive protein immobilized screws (Coated screws) were removed from the rabbits' sacrum. The desorbtion procedure is performed with the Bandelin, Sonorex (Germany) model ultrasonic cleaner for $30 \mathrm{~min}$ with incubated Titanium screw samples inside of $0.5 \mathrm{ml}$ of deuterium solution for each. And this solution was analyzed in NMR to detect residual protein.

\section{Experiment on Rabbits (In vivo part of the study)}

A total of 15 sexually and skeletally mature white New Zealand female rabbits (8 months old, 4- 5 $\mathrm{kg}$ body weight) were obtained from Baskent University Medical Faculty Animal Research Center, Ankara, Turkey. The animals had free access to water and standard rabbit chow. After 15 days of acclimatization, rabbits were randomly allocated to three groups, groups. Group $1(\mathrm{~N}=5)$ : Control group, no induction of osteoporosis but uncoated screws were inserted into the right sacrum through sacral 1 pedicle. Group $2(\mathrm{~N}=5)$ : Induction of osteoporosis and uncoated screws were applied to the right sacrum through sacral 1 pedicle. Group $3(\mathrm{~N}=5)$ : Induction of osteoporosis and bone morphogenetic protein-2 (rhBMP-2) coated screws was inserted into the right sacrum through sacral 1 pedicle. The characteristisc of the groups are shown on the Table 3.

Osteoporosis was experimentally induced in 10 rabbits by a combination of bilateral ovariectomy and systemic corticosteroid administration as described in the literature [25]. Bilateral ovariectomy was performed through a sagittal medial laparotomy under general anesthesia with intramuscular injection 
of $0.5 \mathrm{ml} / \mathrm{kg}$ xylazine (Rompun, Bayer, Leverkusen, Germany) and $1.5 \mathrm{ml} / \mathrm{kg}$ of ketamine $\mathrm{HCl}$ (Ketolar, Parke-Davis, Barcelona, Spain) 1:3. Antibiotic prophylaxis with cefazole $(100 \mathrm{mg} / \mathrm{kg}$ ) (Sefazol Mustafa Nevzat Medicine Industry, Istanbul/Turkey) was administered before and during the 5 days following surgery. Two weeks postoperatively, we started to inject methylprednisolone hemisuccinate (MPH) at a daily dose of $1 \mathrm{mg} / \mathrm{kg} /$ day for 4 weeks through intramuscular way. Six weeks after ovariectomy, we approached through a median incision at the level of the posterior iliac spine and 2 centimeters lateral to the median line under sterile conditions. The lumbar 5 tranverse process and sacral 1 protuberance were palpated. Then, we inserted uncoated screws to group 1 and 2 and coated screws to group 3 into right sacrum through right sacral 1 pedicle. During surgical procedures, all rabbits were anesthetized and antibiotic profilaxis were used according to the protocol which has been descibed at the above lines. The research complied with national legislation and with Baskent University Medical Faculty Ethical committee approval.

Table 3: The characteristics of the groups.

\begin{tabular}{lll}
\hline Groups & & \\
\hline Group 1 & No osteoporosis & Uncoated screw insertion through S1 pedicle \\
$(n=5)$ & to the sacrum \\
Group 2 & Osteoporis & Uncoated screw insertion through S1 pedicle \\
$(n=5)$ & induction & to the sacrum \\
Group 3 & Osteoporis & Coated screw insertion through S1 pedicle to \\
$(n=5)$ & induction & the sacrum \\
\hline${ }^{*}$ Bone morphogenetic protein-2 (rhBMP-2)
\end{tabular}

Preparation of Bone tissues for Histopathological Analysis

Twelve weeks after the insertion of the screws, rabbits were euthanized at the end of the study for the purpose of sample collection by intracardiac administration of sodium pentobarbital (50 $\mathrm{mg} / \mathrm{kg}$ ) (Pentotal, Abbott, Illinois, U.S.A.). Following euthenasia of the rabbits, right sacral region of each rabbit's was carefully dissected to harvest sacrum containing the screw, and we extracted each screw from the sacrum. Then, to fix the sacrums, each sacrum seperately was immersed in 10\% neutral buffered formaldehyde for 48 hours. Later the fixation of the specimens, each sacrum was dehydrated by using ascending concentration of ethanol and immersed in $20 \%$ formic acid solution for twenty hours to provide decalcification of these sacrums [26]. When decalcification was completed, we rinse the specimens in water briefly and transfer to ammonia solution to neutralize acids left in specimens for 30 minutes. And we washed the specimens in running tap water about 24 hours. Later, we performed routine paraffin embedding. Samples within the paraffin blocks were then cut along the long axis of the screws by using a Leica 1600 diamond saw microtome (LeicaSpA, Milan, Italy). Lastly, sections of $4 \mu \mathrm{m}$ in thickness were obtained and stained according to hematoxylin and eosin (H\&E) staining protocol [27]. Finally, we processed them for routine histopathological analyses using a light microscope
(Carl Zeiss GmbH, Jena, Germany).

Statistical Methods for Evaluation of Histopathologic Results

We evaluated all histopathologic results with Mann Whitney $U$ test using SPSS 11 (SPSS, Chicago, IL, USA). A value of $p<0.05$ was set to be statistically significant. We characterized the histopathologic findings in three features. Firstly, Bone: new bone, lameller woven structure formation accepted as excellent bone formation, New bone formation but minimal or no lameller formation accepted as sufficient bone formation, minimal new bone formation but no lameller formation accepted as insufficient bone formation, no new formation accepted lacking bone formation. Secondly, Fibrosis: we classified fibrosis in three grade; mild fibrosis, moderate fibrosis and serious fibrosis. Lastly, Inflammation: we also graded inflammation in three grade; mild inflammation, moderate inflammation and serious inflammation.

\section{Results}

\section{Scanning Electron Microscope Analysis}

We analysed the screws in the control group and in the plasma polymerization performed group. And we took the images of the screws in both groups under scanning electron microscope (SEM), which showed the partial smoothness obtained with plasma polymerization onto the Titanium screws. Deposition thickness of these screws is shown in Figure 3. On the left side of the Figure 3 (Figure 3a), it is observed that the roughness of the surface of the screw before the plasma polymerization while on the right side of the figure 3 the surface of the screw is observed flat after the plasma polymerization.

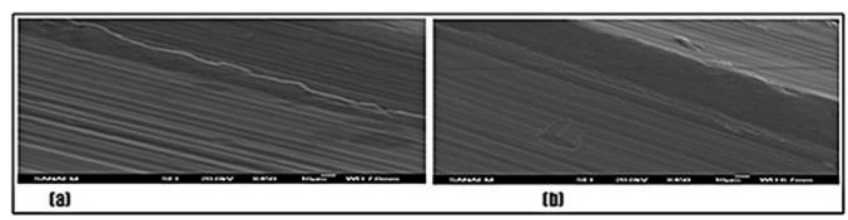

Figure 3: Scanning electron microscope (SEM) images of (a) unmodified (b) plasma treated Titaniumscrew (x450). Plasma polymerization process causes the fill effect for the surface roughness depend on deposition thickness.

The effectivity of plasma polymerization process is shown with filling effect of the surface roughness, and it depends on deposition thickness. Scanning electron microscope images of (Figure 3a) unmodified (x 450) and modified screws of (Figure 3b) show the changes of the surface from the rough surface of the unmodified screw to the smooth surface of the modified sccrew. Thus, this surface change is the proof of the effectivity of the plasma polymerization technique on the Titanium screw Figure 3a, 3b. 


\section{Stylus Probe and Non-Contact Surface Profiler}

Examination of surface thickness and roughness were carried with two different kinds of samples: I: Samples were coated by plasma polymerization technique with monomer; cysteamine figure 4. II: Samples were etched with oxygen plasma (exposure time: 20 min., pressure:5 torr ) then coated by plasma polymerization discharge with monomer cysteamine which is Figure 4.

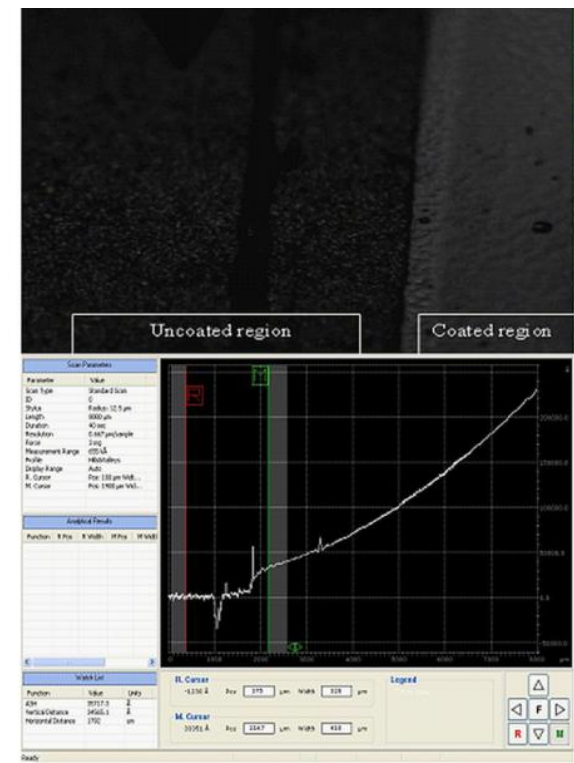

Figure 4: Boundary of uncoated and coated sides of plasma polymerized Titanium reference. a) Uncoated region is on the left side and b) coated region on the right side

Figure 4 presented by DekTac 6M Stylus Probe Surface Profiler. It showed that film thickness is $34.5 \mathrm{~nm}$ for sample I which is on the left side of the Figure 4 and for sample II $27.3 \mathrm{~nm}$ which is on the right side of the Figure 4. Oxygen plasma treatment before plasma polymerization technique caused thin film layer because of etching effect.

Moreover, this surface roughness values were detected from non-contact surface profiler (Zygo New View 6200) in Figure 5. It showed that Titanium reference has a surface roughness values that $917 \AA$, which is shown on the left side of the Figure 5, was improved by oxygen etching then plasma polymerization with cysteamine to the value of 2791 $\AA$, which is shown on the right side of the Figure $5 \mathrm{a}$ ) Unmodified figure b) oxygen etched then plasma polymerization.

According to the results both to the obtain thin film and the improve to the osteointegration with physical roughness the oxygen pre-treatment is applied for Titanium screws. In addition this film layer formation is claimed that plasma polymerization of cysteamine.
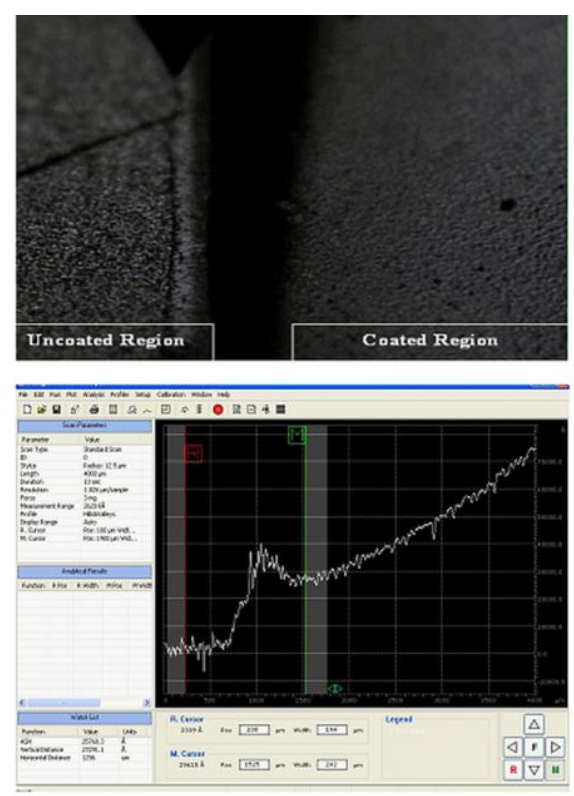

Figure 5: a) Unmodified region is shown on the left side b) Modified region (oxygen etched then plasma polymerization) is shown on the right side.

\section{X-ray Absorption Spectroscopy Analysis}

(XPS)

Electron spectroscopy for chemical analysis (ESCA) spectrums was used to determine the quality of the coating and to get the knowledge of surface chemistry of the polymerized Titanium screws. It was aimed to see the sulfur peaks, from the analysis of the first two layer of the coating were obtained by ESCA measurements. Consequently, it was understood that the surface included the thiol $\left(-\mathrm{NH}_{2}\right)$ functional group coating before the surface activation by glutaraldehyde as it is desired. Besides that, any peak value that belongs to Titanium was not seen from the spectrum of coated Titanium screw surface. This is also shown the coating is homogenously dissipated on through the screw and it is said that the quality of the surface at the level of desired one (Figure 6).

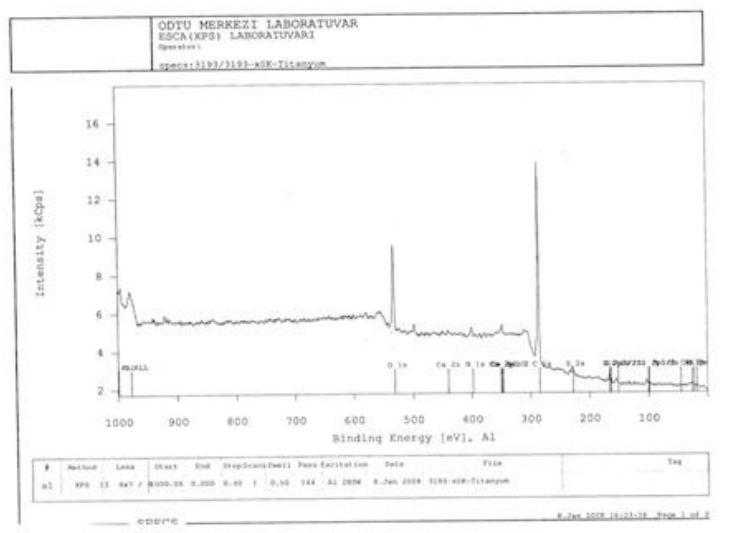

Figure 6: Elemental analysis of Titanium screws after plasma polymerization. 
This result is obtained from first layer of plasma polymerized film. Then this spectrum is repeated with the change of sample angle to obtain chemical structure of film layer more deep close to the surface (Table 1). Table 1 shows that plasma polymerized film had a composition of $79.5 \% \mathrm{C}, 18 \%$ $\mathrm{O}$ and \%2.6 S. This was the proof that the film layer composition changed through the Titanium screw surface because of thiol groups orientate to the metal surface. And these thiol groups behave like to the surface to assemble monolayer main idea that thiol group likes the gold surface and alkanthiols hydrocarbons are always has a position of orientated structure on gold. It is claimed that same behavior is supported on Titanium surfaces [22-24].

\section{Contact Angle Measurement}

The contact angle is determined as this inner angle between solid surface and water drop. During the experiments, it is known that hydrophilicity decreases while contact angle increases in Figure 7. In this study, contact angle measurements of control group, plasma treated and activated Titanium screw samples are examined. Total $46.2^{\circ}$ decrease on the contact angle proved the modified thin layer constituted on the screws are stabilized and activated through the bioactive protein immobilization. Table 2 shows that increase hydrophilicity of the screws surfaces increases according to the surface modifications for each step. The results are five replicates of each sample.

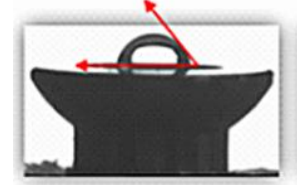

[a]

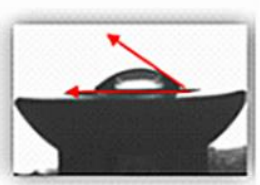

[b]

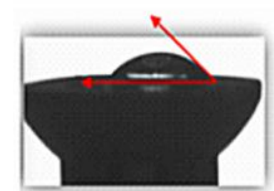

[c]
Figure 7: The pictures of sensile drops for surfaces (a) unmodified (b) plasma modified, (c) activated surfaces.

Generally amine groups represents increasing of hydrophilic character, thiol is more hydrophobic than the amine groups. So it is the clue that proper orientation of chemical groups. These results are also supported by chemical characterizations. In the final step, after the glutaraldehyde activation the contact angle is decreased showing that the amine groups are converted to the aldeyde groups that are more hydrophilic and stable that is the main criteria for protein immobilization.

\section{Immobilization of Bioactive Protein}

We used two different approaches in the nuclear magnetic resonance spectroscopy analysis. Firstly, experimental group is used to understand the activity of rhBMP-2 with time. Throughout the experiment, we took three samples after $2 \mathrm{~h}, 5 \mathrm{~h}$, and we obtained the nuclear magnetic resonance spectroscopy analysis as shown in Figure $8 \mathrm{a}, \mathrm{b}$. We observed that characteristic ppm values of rhBMP-2 decreased with time. These decreased ppm values of rhBMP-2 at the nuclear magnetic resonance spectroscopy with time proved that increased level of immobilized active protein onto the screw surfaces. It means that the procedure effectively provides protein immobilization onto screws' surface.

a)

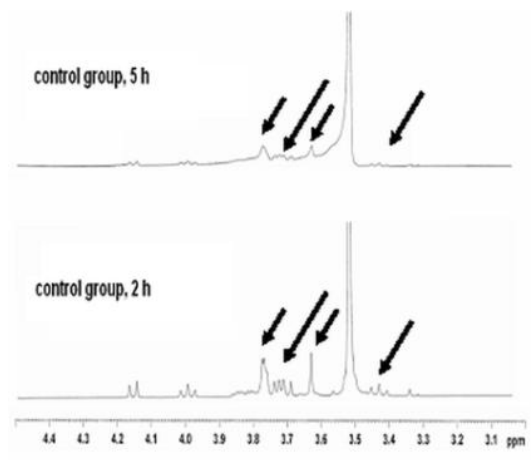

b)

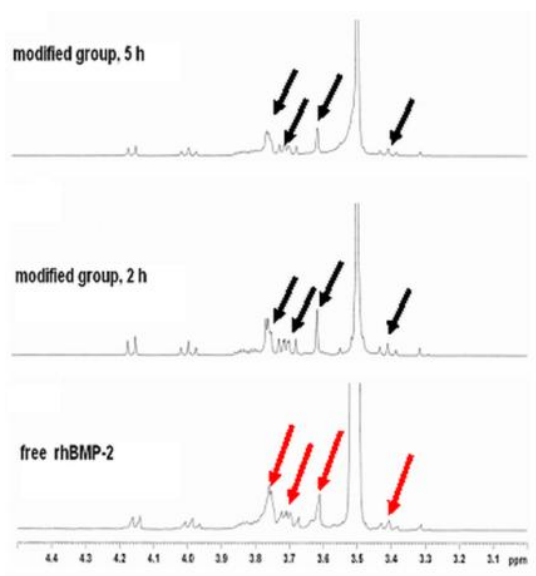

Figure 8: a) Pure Titanium screw b) Plasma polymerization + activation+ BMP. The red arrows on the right side of the figure show predicted characteristic peaks of active protein.

The red arrows at the Figure $8 \mathrm{~b}$ show that predicted characteristic peaks of active protein. We generated the analyses comparing of each free bioactive protein spectrum. Modification of Titanium screws' surface led to increase the immobilization rate of the rhBMP-2 onto screws' surface as to unmodified Titanium screw surfaces. In Figure $8 \mathrm{a}$, the rate of increment of the concentration of rhBMP-2 was very fast with time, which shows adsorption of the protein by physical forces. However, in Figure 8b, the decreased signal peaks of bone morphogenetic protein 2 (rhBMP-2) in low ratio showed that bone morphogenetic protein 2 was adsorbed chemically with time. In addition this second experimental setup was used for the examination of the remaining bioactive protein layer on the screws after in-vivo studies. Desorption experiment was generated with 5 
screws which were exposed surgical operation and continues dynamic body fluid.

Nuclear magnetic resonance spectroscopy of bioactive protein immobilized on Titanium screws: Desorption experiment

The notation A-E describes the 5 different screws. Spectrums showed in Figure 9 proved the bioactive protein layer on the screws still remained in spite of the operation and body fluid with the same characteristic peaks of rhBMP-2.

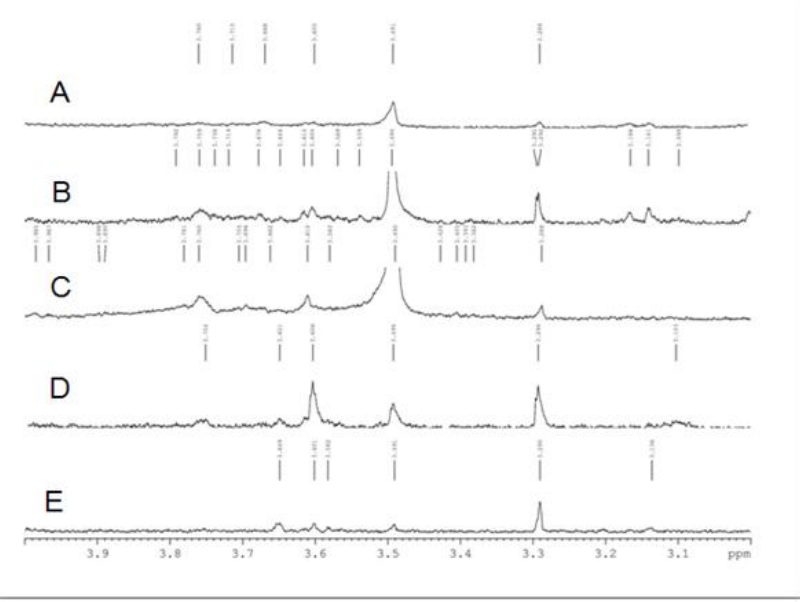

Figure 9: Nuclear magnetic resonance spectroscopy of bioactive protein immobilized on itanium screws: Desorption experiment.

\section{Gross Inspection and Manual Evaluation of the Screws}

After surgical procedure, we did not observed loosening of any inserted screw into sacrum in group 1 and group 3, but observed and palpated that loosening of the screws in group 2.

\section{Histopathologic Analysis}

Group 1: (Rabbits with healthy bone and uncoated screws were inserted into the right sacrum through sacral 1 pedicle). Group 2: Induction of osteoporosis and uncoated screws were inserted into the right sacrum through sacral 1 pedicle. Group 3: Induction of osteoporosis and bone morphogenetic protein-2 (rhBMP-2) coated screws was inserted into the right sacrum through sacral 1 pedicle. The characteristisc of the groups are shown on the table 3 . Histopathologic sections harvested from group 1 , group 2 and group 3 are shown in Figure 10 a, b; 10 $\mathrm{c}, \mathrm{d} ; 10 \mathrm{e}, \mathrm{f}$, respectively. In group 1 we observed no fibrous tissue, no new bone formation (Figure $10 \mathrm{a}, \mathrm{b}$ ) but we observed histopathologically new bone formation characterizing in woven and lamellar structure with coated screws in group 3 (Figure $10 \mathrm{e}$, f). In osteoporotic bone with uncoated screw (Group
2) and in osteoporotic bone with coated screw with rhBMP-2 (Group 3) are illustrated in figure c, $d$ and figure $e, f$ respectively. In these figures, histopathologically, the osteoporotic rabbits' sacrum in group 2 (Figure10 c, d) showed larger fibrotic areas and less osteoinductive areas than the osteoporotic rabbits' sacrum in group 3 (Figure $10 \mathrm{e}, \mathrm{f}$ ). Moreover, the osteoporotic rabbits' sacrum in group 3 showed the osteoinductive areas with woven and lamellar bone structure (Figure $10 \mathrm{e}, \mathrm{f}$ ).

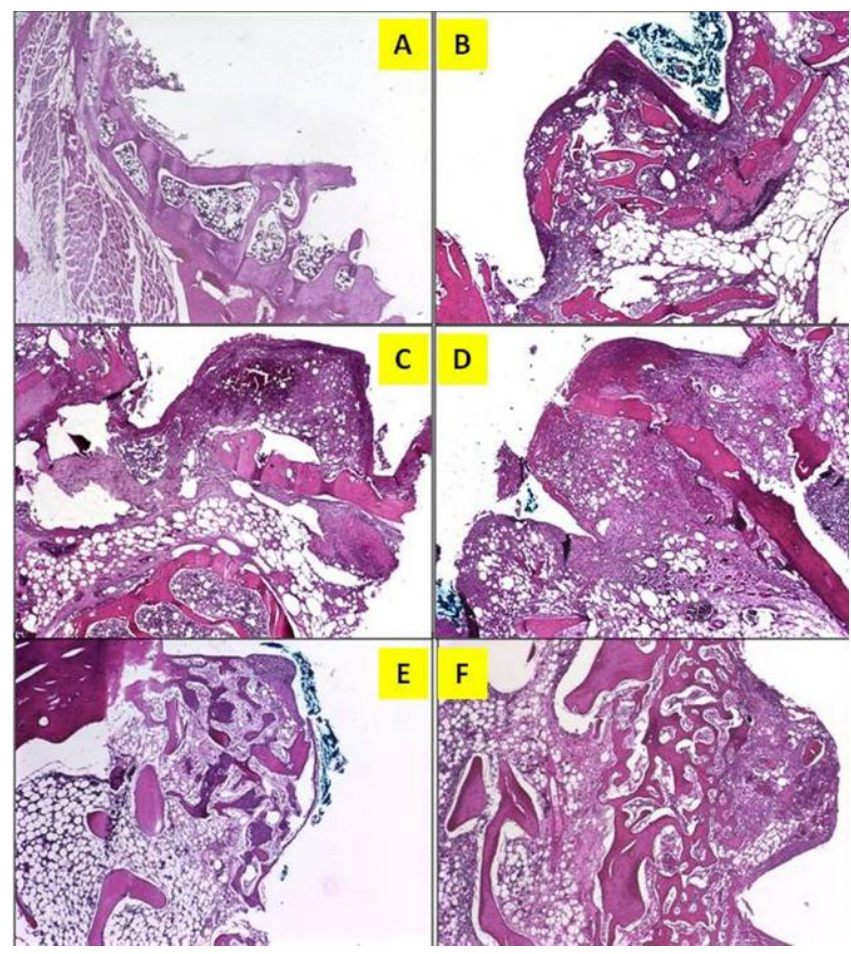

Figure 10: Hematoxylin and eosin staining of tissue and cell sections of the groups.(Group 1), (Figure 10 a,b): Uncoated screws were inserted to the nonosteoporotic rabbits' sacrum through sacral 1 pedicle. The bone sections harvested from this group showed that normal bone structure and no fibrosis and no inflammation. (Group 2), (Figure $10 \quad c, d)$ : Uncoated screws were inserted to the osteoporotic rabbits' sacrum through sacral 1 pedicle. The bone sections harvested from group 2 showed that osteoporosis, fibrosis and inflammation, also minimal new bone formation without any woven or lameller formation. (Group 3), (Figure 10 e,f): Bone morphogenic protein 2 (rhBMP-2) coated screws were inserted to the osteoporotic rabbits' sacrum through sacral 1 pedicle. At the bone sections harvested from group 3 showed that new bone formation characterizing in woven and lamellar structure with minimal fibrosis and no inflammation.

\section{Results of Statistical Analysis}

We used Mann Whitney $U$ test to compare the groups. Results with $p$-values $<0.05$ were considered statistically significant. And we compared group 2 against group 3; group 1 against group 3. Firstly, Group 2 against group 3: Group 3 has better bone formation, less fibrosis and less inflammation against group 2 and these results showed significant statistical difference (Table 4). Secondly, Group 1 against group 3: In group 1, we did not observe any new bone. Lastly, regarding new bone formation, group 3 had better new formation and showed 
significant statistical difference, but regarding fibrosis and inflammation, we did not find any significant statistical difference between group 1 and group 3 (Table 5).

Table 4: Comparison of the Group 3 against group 2. Group 3 has better bone formation, less fibrosis and less inflammation against group 2 and these results showed significant statistical difference.

\begin{tabular}{|c|c|c|c|c|}
\hline & GROUPS & $\mathrm{N}$ & Mean Rank & Sum of Ranks \\
\hline \multirow[t]{2}{*}{ BONE } & $\begin{array}{l}\text { Group } 2 \text { Osteoporosis } \\
\text { Induction Uncoated } \\
\text { Screw }\end{array}$ & 5 & 3,00 & 15,00 \\
\hline & $\begin{array}{l}\text { Group } 3 \text { Osteoporosis } \\
\text { Induction Coated Screw } \\
\text { Total }\end{array}$ & $\begin{array}{r}5 \\
10 \\
\end{array}$ & 8,00 & 40,00 \\
\hline \multirow[t]{2}{*}{ INFLAM } & $\begin{array}{l}\text { Group } 2 \text { Osteoporosis } \\
\text { Induction Uncoated } \\
\text { Screw }\end{array}$ & 5 & 7,80 & 39,00 \\
\hline & $\begin{array}{l}\text { Group } 3 \text { Osteoporosis } \\
\text { Induction Coated Screw } \\
\text { Total }\end{array}$ & $\begin{array}{r}5 \\
10\end{array}$ & 3,20 & 16,00 \\
\hline \multirow[t]{2}{*}{ FIBROSIS } & $\begin{array}{l}\text { Group } 2 \text { Osteoporosis } \\
\text { Induction Uncoated } \\
\text { Screw }\end{array}$ & 5 & 8,00 & 40,00 \\
\hline & $\begin{array}{l}\text { Group } 3 \text { Osteoporosis } \\
\text { Induction coated Screw } \\
\text { Total }\end{array}$ & $\begin{array}{r}5 \\
10\end{array}$ & 3,00 & 15,00 \\
\hline
\end{tabular}

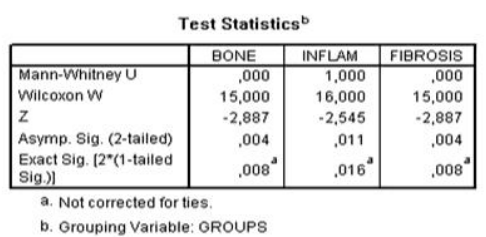

\section{Discussion}

Titanium made screws and rods are used in spinal surgery for the stabilization of the vertebral column [1, 2, 4]. These Titanium screws provides only temporal stabilization of the vertebral column, so bone fusion is crucial to sustain stability of the spinal column $[1-5,7]$. While Spinal fusion occurs within 6 months following spinal surgery, Titanium screws should continue to the stability of the spinal column [1$4,8-10]$. In this period, loosening of the Titanium screws lead to instability and mobility of the spinal segments, and both of them cause insufficient bone fusion, but plentiful fibrosis and granulation tissue [2, $5,6,8]$. Therefore, the interaction between the screw and bone has vital importance.

In osteoporotic cases, loosening of the screw and its results are major ineffectivity factors in the spinal stabilization procedures [1, 3, 6, 28]. The weakness of the osteoporotic bones causes low pull out strain and loosening of the screws [8]. Then, it develops incomplete fixation and pseudoartrosis between the vertebral body, pedicle and screw $[5,6$, 28]. In different studies, histopathological examination of the interface between screws and vertebral body shows fibrosis around the screws instead of new bone formation in osteoporotic vertebral bodies thanks to ineffective spinal stability [5, 6, 28].

Cement-augmented screws were reported to offer a higher resistance to pullout forces compared with the standard screws. And these cement augmented screws might provide increased average pullout resistance of primary or revision-cemented screws ranging from $150 \%$ to $250 \%$ of standard screws [30-32]. However, the drawbacks of cementaugmented screws, either cannulated or inserted using the vertebroplasty technique, are the significant potential of cement leakage, with approximately one third of cases presenting leakage in the spinal canal, and the risk of pulmonary embolism [33]. Cement application can provide a host for an infection and requires a high exothermic polymerization temperature. Moreover, the use of polymethylmethacrylate (PMMA) (Cement) causes increased fractures risk for adjacent verebra [33, 34]. Furthermore, in contrast to the results presented in biomechanical studies [32, 34], and our clinical experience show that using of the cement during the revision of loosened screw or directly using of the cement to strengten pullout force of the screws may provide immediate stability, but it causes more fibrosis and more loosening of the screws with time [32, 34].

Table 5: Comparison of the Group 1 against group 3 . Regarding new bone formation, group 3 had beter new bone formation and showed significant statistical difference, but regarding fibrosis and inflammation, the results did not showed any significant statistical difference between group 1 and 3.

Mann-Whitney Test
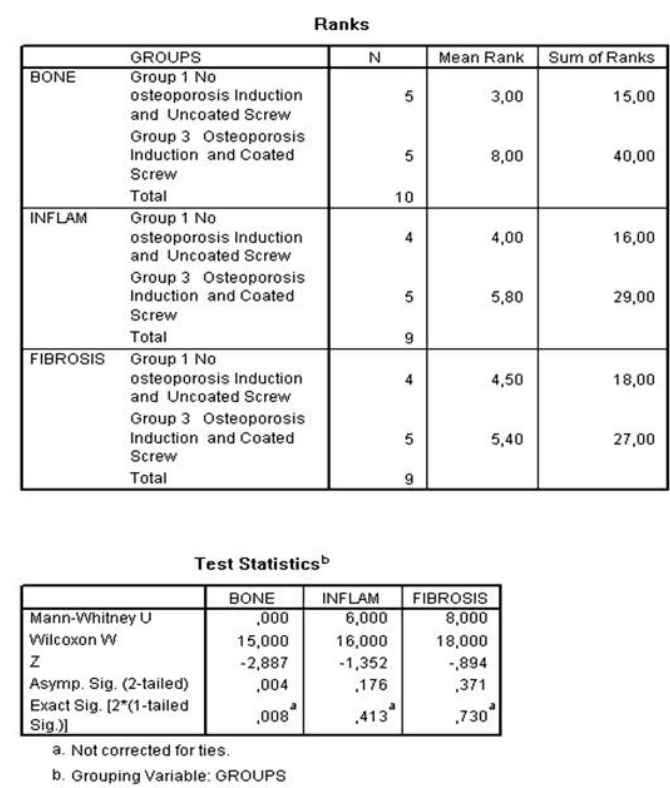

Up to now, spinal surgeons have had problems to overcome to the loosening of the screws in patiens with osteoporosis. Different methods are still investigated to decrease the failure rate of the spinal fusion [29-32, 34-36, 40-43].

Different bone graft materials provides induction of bone fusion in three ways which are osteogenesis, osteoconduction and osteoinduction 7 , $9,10,35-37]$. Firstly, osteogenesis inductive grafts provide new bone formation, and this processs is dependent on the presence of live osteoprogenitor bone in the graft $[7,9,10,35-37]$. They have the capacity to differentiate into bone-forming osteogenic 
precursor cells [7, 9, 10, 35-37]. Secondly, osteoconduction is establishing physical framework for the ingrowth of neovasculature and the infiltration of osteogenic precursor cells into the graft site. For example, to provide osteoconduction, cancellous autografts, allografts, demineralized bone matrix, hydroxyapatite, collagen, and calcium phosphate can be used [7, 9, 10, 35-37]. Lastly, osteoinduction is the process that graft materials can induce stem cells to differentiate into mature bone cells [7, 9, 10, 35-37]. For instance, bone morphogenic proteins and demineralized bone matrix provides osteoinduction [7, 9 , 10, 35-37]. And, this process is related with the presence of bone growth factors within the graft material or as a supplement for the bone graft. Additionally, autograft and allograft bone have a much lesser degree some osteoinductive features [7, 9, 10, 35-37]. These explained mechanisms can only occur in the condition of the stabilization of the vertebral segments.

Because of the reasons mentioned above, it is obvious that spinal surgeons need to find new strategies to prevent the risk of pedicle screw loosening and to increase the endurance limits for pedicle screw fixations [34-44].

Bone morphogenetic proteins (BMPs) are members of the TGF- $\beta$ superfamily and play a critical role in skeletal development, bone formation and stem cell differentiation [45]. Disruptions in BMP signaling result in a variety of skeletal and extraskeletal anomalies [45, 46]. Among BMPs, BMP-2 has very strong osteoinductive activity [45-47]. On the one hand, BMP-2 can induce the osteogenic differentiation of mesenchymal cells and de novo orthotopic or ectopic bone formation [14-16, 45-47]. On the other hand, its expensiveness, requirement of high dose (1 $\mathrm{mg}$ BMP-2/mL defect), and its short half-life in vivo environment can cause uncontrolled and abundant releasing of this protein [16-19]. To overcome these problems, BMP-2 delivery systems such as collagen gels, sponges, scaffolds, hyaluronic acid, and fibrin gels for prolonged, local release of BMP-2 have been studied [17-21, 47]. However, these systems have problems such as uncontrolled release rates. Releasing of BMP-2 for only a short period or a high initial burst of release leads to bone overgrowth and pressure effects on the neural tissue or insufficient bone formation, screw loosening and fibrosis [14, 47].

In this study, we used plasma polymerization technique on screw surfaces to provide active amine binding sites for anchoring of recombinant bone morphogenetic protein-2 (rhBMP-2) on screw surface. The proof for immobilization and successful anchoring of rhBMP-2 on modified Titanium surfaces were demonstrated (Fig. 6, 7, 8, 9).

The clinical success of spinal stabilization is highly dependent on the cell adhesion, matrix production, anti-inflammatory, and mineralization properties of the implant materials [7, 10]. We demonstrated these effects with rhBMP-2 coated Titanium screws in osteoporotic female rabbit bones through histopathologic analysis of the screw and bone interface. Plasma polymerization technique as a covering method of Titanium screws with the rhBMP-2 providing the anchoring point and immobilization of the rhBMP-2. And this technique may provide suitable method for sustained release of rhBMP-2 because of two reasons. Firstly, in histopathological sections, we observed copious osteoinductive activity in osteoporotic rabbits applied rhBMP-2 coated screw, but we observed insufficient osteoinduction along with abundant fibrosis and osteoclastic activity in rabbits applied uncoated screws. Secondly, according to our nuclear magnetic resonance spectroscopy results, after the in vivo experiment, we extracted the coated screws from the rabbits. Then we measured that whether or not there was residual protein on the coated screw. And we find that the wave length of this protein was the same of rhBMP-2. Morever, in a previous study [14], large doses of rhBMP-2 and its immediate releasing from the anchoring points led to immune response and bone overgrowth from the defect site. On the contrary to this, we did not observed any exaggerated inflammation and bone overgrowth in histopathologic sections of the sacrums extracted from group 3 on which we induced osteoporosis and applied rhBMP2 protein coated screws. These findings also support that plasma polymerization coating method on Titanium screws provide slow and controlled releasing of rhBMP-2. Finally, it is noteworthy that we detected the residual protein on the coated screw after finishing in vivo study using nuclear magnetic resonance spectroscopy. These results also pointed that there was residual protein on the coated screw as shown in Figure 9. This finding also supported that plasma polymerization technique can be an appropriate immobilization technique for rhBMP-2.

We also assesed statistically our histopathologic results. We compared three features of the histologic sections, new bone formation, fibrosis and inflammation respectively, in three groups. Our views also statistically confirmed that rhBMP-2 provides new bone formation in group 3 and less fibrosis and less inflamation than in group 2, but no difference between groups 1 and group 3 regarding fibrosis and inflammation. In group 1, we did not induced osteoporosis, so bone and uncoated screw bonding developed better than group 2 which we induced osteoporosis and it caused screw loosening and mobility between the bone and screw. Notably, we induced osteoporosis in group 2 and 3, but we did not observe fibrosis and inflammation in group 3 on the contrary as in group 2. In our opinion, the screw mobility in group 2 due to osteoporosis led to fibrosis and inflammation. rhBMP-2 coated screws break the cycle of inflammation, fibrosis and screw loosening in group 3, and these factors contribute new bone formation. 
Finally, our histopathological examination and nuclear magnetic resonance spectroscopy results show that coating the screws with rhBMP-2 using plasma polymerization method provides osteoinduction in osteoporotic rabbits without causing bone overgrowth, exaggerated fibrosis and inflammation. Thus, plasma polymerization technique being a novel coating method with rhBMP-2 could may open new horizon in the field of the spinal surgery.

\section{References}

1. Halvorson TL, Kelley LA, Thomas KE, Whitecloud TS, Cook SD. Effects of bone mineral density on pedicle screw fixation. Spine. 1994;19:2415-2420,

2. Hu SS. Internal fixation in the osteoporotic spine. Spine. 1997;22:43- 48.

3. Kiner DW, Wybo CD, Sterba W, et al. Biomechanical analysis of different techniques in revision spinal instrumentation. Spine. 2008; 33: 2618-2622.

4. Daubs MD, Lenke LG, Cheh G, et al. Adult spinal deformity surgery. Spine. 2007; 32:2238-2244.

5. Emami A, Deviren V, Berven S, et al. Outcome and complications of long fusion to the sacrum in adult spinal deformity. LuqueGalveston, combined iliac and sacral screws, and sacral fixation. Spine. 2002; 27: 776-786.

6. Kim YJ, Bridwell KH, Lenke LG, et al. Pseudoarthrosis in long adult spinal deformity instrumentation and fusion to the sacrum prevalence and risk factor analysis of 144 cases. Spine. 2006; 31:2329-2336.

7. Boden SD. Overview of the biology of lumbar spine fusion and principles for selecting a bone graft substitute. Spine. 2002; 27:2631.

8. Wittenberg $\mathrm{RH}$, Shea M, Swartz DE, et al. Importance of bone mineral density in instrumented spine fusions. Spine. 1991; 16:647652.

9. Kalfas IH. Principles of bone healing. Neurosurg Focus. 2001; 15:4-10.

10. Muschler GF, Lane JM, Dawson EG. The biology of spinal fusion, in Cotler JM, Cotler HP: Spinal Fusion Science and Technique. Berlin: Springer-Verlag, 1990: 9-21.

11. Kaufman $\mathrm{HH}$, Jones $\mathrm{E}$. The principles of bony spinal fusion. Neurosurgery. 1989; 24:264-270.

12. David L, Feige JJ, Bailly S. Emerging role of bone morphogenetic proteins in angiogenesis. Cytokine Growth Factor Rev. 2009;20:203-212.

13. King GN, King N, Cruchley AT, Wozney JM, Hughes FJ. Recombinant human bone morphogenetic protein-2 promotes wound healing in rat periodontal fenestration defects. J Dent Res. 1997;76:1460- 1470 .

14. Shields LB, Raque GH, Glassman SD, et al. Adverse effects associated with high-dose recombinant human bone morphogenetic protein-2 use in anterior cervical spine fusion. Spine. 2006;31: 542 547.

15. Zellin G, Linde A. Importance of delivery systems for growthstimulatory factors in combination with osteopromotive membranes. An experimental study using rhBMP-2 in rat mandibular defects. J Biomed Mater Res. 1997; 35:181-190.

16. McClellan JW, Mulconrey DS, Forbes RJ, Fullmer N. Vertebra bone resorption after transforaminal lumbar interbody fusion with bone morphogenetic protein (rhBMP-2). J Spinal Disord Tech 2006;19: 483-486.
17. Kim J, Park Y, Tae G, Lee KB, Hwang CM, Hwang SJ, et al. Characterization of low-molecular-weight hyaluronic acid-based hydrogel and differential stem cell responses in the hydrogel microenvironments. J Biomed Mater Res. 2009;88:967-975.

18. Kim J, Kim IS, Cho TH, Lee KB, Hwang SJ, Tae G, et al. Bone regeneration using hyaluronic acid-based hydrogel with bone morphogenic protein-2 and human mesenchymal stem cells. Biomaterials. 2007; 28:1830-1837.

19. Lee TC, Ho JT, Hung KS, Chen WF, Chung YH, Yang YL. Bone morphogenetic protein gene therapy using a fibrin scaffold for a rabbit spinal-fusion experiment. Neurosurgery. 2006; 58:373-380.

20. Jeon O, Song SJ, Yang HS, Bhang SH, Kang SW, Sung MA, et al. Long-term delivery enhances in vivo osteogenic efficacy of bone morphogenetic protein- 2 compared to short-term delivery. Biochem Biophys Res Commun. 2008; 369:774-780.

21. Mummaneni PV, Pan J, Haid RW, Rodts GE. Contribution of recombinant human bone morphogenetic protein-2 to the rapid creation of interbody fusion when used in transforaminal lumbar interbody fusion: a preliminary report. Invited submission from the joint section meeting on disorders of the spine and peripheral nerves. J Neurosurg Spine. 2004; 1:19-23.

22. Treves $C 1$, Martinesi M, Stio M, Gutiérrez A, Jiménez JA, López MF. In vitro biocompatibility evaluation of surface-modified titanium alloys. J Biomed Mater Res. 2010;15:1623-1634.

23. Hanawa T. In vivo metallic biomaterials and surface modification. Elsevier Materials Science \& Engineering. 1999; 267: 260-266.

24. Cokeliler D, Goktas H, Tosun PD, Mutlu S, Infection Free Titanium Alloys By Stabile Thiol Based Nanocoating, Journal of Nanoscience and Nanotechnology. 2010; 10:2583-9.

25. Santos Castañeda, Emilio Calvo, Raquel Largo, Rocío González-González, Concepción de la Piedra, Manuel Díaz-Curiel, Gabriel Herrero-Beaumont. Characterization of a new experimental model of osteoporosis in rabbits. J Bone Miner Metab. 2008;26:5359 .

26. Verdenius HHW and Alma L, A quantitative study of decalcification methods in histology. J Clin Pathol. 1958;11: 229236.

27. Sheehan, D.C. and Hrapchak, B.B. : Theory and Practice of Histotechnology, 2nd Edition; Battelle Memorial Institute, Columbus, $\mathrm{OH}, 1987$.

28. Aurori BF, Weierman RJ, Lowell HA, et al: Pseudoarthrosis after spinal fusion for scoliosis. A comparison of autogenic and allogenic bone grafts. Clin Orthop. 1985;199:153-158.

29. Moore DC, Maitra RS, Farzo LA, Graziano GP, Goldstein SA Restoration of pedicle screw fixation with an in situ setting calcium phosphate cement. Spine. 1997; 22:1696-1705

30. Chang MC, Liu CL, Chen TH. Polymethylmethacrylate augmentation of pedicle screw for osteoporotic spinal surgery: a novel technique. Spine. 2008;33:317-324.

31. Renner SM, Lim TH, Kim WJ, Katolik L, An HS, Andersson GB. Augmentation of pedicle screw fixation strength using an injectable calcium phosphate cement as a function of injection: timing and method. Spine. 2004; 29:212-216.

32. Fransen P. Increasing pedicle screw anchoring in the osteoporotic spine by cement injection through the implant. $J$ Neurosurg. 2007; 7: 366-369.

33. Chen W-J, Kao Y-H, Yang S-C, et al. Impact of cement leakage into disks on the development of adjacent vertebral compression fractures. J Spinal Disord Tech. 2010; 23:34-39.

34. Bullmann V, Schmoelz W, Richter $M$, et al. Revision of cannulated and perforated cement-augmented pedicle screws. Spine. 2010; 35: 932-939.

35. Bucholz RW, Carlton A, Holmes RE: Hydroxyapatite and tricalcium phosphate bone graft substitutes. Orthop Clin North Am. 
1987;18:323-334.

36. Spivak JM, Neuwirth MG, Labiak JJ, Kummer FJ, Ricci JL. Hydroxyapatite enhancement of posterior spinal instrumentation fixation. Spine. 1994; 19: 955-964.

37. Sellers RS, Peluso D, Morris EA. The effect of recombinant human bone morphogenetic protein-2 (rhBMP-2) on the healing of full-thickness defects of articular cartilage. J Bone Jt Surg Am. 1997;79:1452-1463.

38. Chen NF, Smith ZA, Stiner E, et al. Symptomatic ectopic bone formation after off-label use of recombinant human bone morphogenetic protein-2 in transforaminal lumbar interbody fusion. J Neurosurg Spine. 2010; 12:40-6.

39. Wong DA, Kumar A, Jatana S, et al. Neurologic impairment from ectopic bone in the lumbar canal: a potential complication of off-label PLIF/TLIF use of bone morphogenetic protein-2 (BMP-2). Spine. 2008; 8:1011-1018.

40. Sarzier JS, Evans AJ, Cahill DW. Increased pedicle screw pullout strength with vertebroplasty augmentation in osteoporotic spines. J Neurosurg. 2002; 96:309-312.

41. Burval DJ, Mclain RF, Milks R, Inceoglu S. Primary pedicle screw augmentation in osteoporotic lumbar vertebrae. Spine. 2007;32: 1077-1083

42. Lotz JC, Hu SS, Chiu DF, et al. Carbonated apatite cement augmentation of pedicle screw fixation in the lumbar spine. Spine. 1997;22: 2716-2723.

43. Wu ZX, Cui G, Lei W, Fan Y, Wan SY, Ma ZS. Application of an expandable pedicle screw in the severe osteoporotic spine: a preliminary study. Clin Invest Med. 2010;33:1-8.

44. Bishop RC, Moore KA, Hadley MN: Anterior cervical interbody fusion using autogeneic and allogeneic bone graft substrate: a prospective comparative analysis. J Neurosurg. 1996;85:206-210.

45. Cook SD, Wolfe MW, Salkeld SL, Rueger DC. Effect of recombinant human osteogenic protein-1 on healing of segmental defects in non-human primates. J Bone Jt Surg Am. 1995;77:734750 .

46. Govender S, Csimma C, Genant HK, Valentin-Opran A, Amit Y, Arbel $\mathrm{R}$, et al. Recombinant human bone morphogenetic protein-2 for treatment of open tibial fractures: a prospective, controlled, randomized study of four hundred and fifty patients. J Bone Jt Surg Am. 2002;84:2123-2134.

47. Wang EA, Rosen V, D'Alessandro JS, Bauduy M, Cordes $P$, Harada $T$, et al. Recombinant human bone morphogenetic protein induces bone formation. Proc Natl Acad Sci USA. 1990;87:2220 2224. 